\title{
EDU-CAR: QUALITATIVE ANALYSIS OF AN INTERVENTION FOR THE DEVELOPMENT OF SOCIO-EMOTIONAL AND CAREER COMPETENCES ${ }^{1}$
}

\author{
Mara Leal, \& Lucy Melo-Silva \\ Department of Psychology, Faculty of Philosophy, Sciences and Letters at Ribeirão Preto, \\ University of São Paulo (Brazil)
}

\begin{abstract}
This study aims to qualitatively analyze the communication strategies used by the psychologist and the participants in a career intervention that aimed at the development of socioemotional and career skills in high school students. A total of 44 students ( $55 \%$ boys, ages: $\mathrm{M}=15.16$, SD = 0.7) from two public high school classes in the interior of São Paulo, Brazil participated in the intervention. The program was structured in two modules, the first one for the work of the socioemotional competences and the second module for the work of the career competences. The program comprised a total of 12 sessions. The sessions were held weekly. The data were obtained through audio records that were transcribed and analyzed based on content analysis. Data were analyzed by intervention session and by classroom. The registration of 20 sessions constitutes the corpus of analysis of this study. Questions about the quality of the activities and about the quality of student participation, in their opinions, were evaluated. The analysis of the frequencies of the registers of the categories of interventions of the psychologist and of the reactions of the students allowed verifying the effectiveness of the intervention. The results show that the school was identified as a place of preparation for work and that the topics covered were considered important for life. Most of the students considered the quality of the activities developed in the intervention as good, and their participation as regular.
\end{abstract}

Keywords: Intervention, qualitative, socio-emotional skills, career development, high school.

${ }^{1}$ Grant \#2015/12677-0, São Paulo Research Foundation (FAPESP). 